\title{
UNA RESPUESTA TOMISTA A LA DESCONSTRUCCIÓN DE LAS RELACIONES MARITALES EN EL MUNDO POSMODERNO*
}

Donald De Marco **

El término "desconstrucción", que 65 proviene de Heidegger y Derrida, se encuentra hoy tan emancipado de sus ataduras filosóficas que no sólo ha pasado a ser parte del fenómeno vernáculo estadounidense, sino que ha adquirido una orientación suficientemente precisa como para hacer de él, de buena fe, un "signo de los tiempos" en nuestro mundo posmoderno. Se pueden enumerar varios ejemplos. Una librería de la universidad del pueblo de Ithaca en el estado de Nueva York, muestra un anuncio en una pared que advierte a sus clientes: "Todo ladrón de libros será desconstruido."1 Un crítico de televisión cree que la clave de la inmensa popularidad del Show de Seinfield yace en su "formato desconstruccionista": no existen compromisos, matrimonios ni bebés y los episodios semana-

* Traducción de Antonio Canizales.

** University of St. Jerome's College, Ontario, Canadá.

'David Lehman, Sign of Times: Deconstruction and the Fall of Paul De Man, 1991, New York, Simon \& Schuster, Chapter 1. 


\section{DONALD DE MARCO}

les no tienen continuidad ni llevan a nada. La feminista Monique Witting clama por "una desconstrucción política del término 'mujer" con el fin de liberar el "mito" que se ha incrustado en él. ¿Cuán difundida se encuentra la desconstrucción en los Estados Unidos? De acuerdo con Jacques Derrida, "Estados Unidos es la desconstrucción". 3 En una respuesta no muy lejos de la verdad, el guionista Mark Horowitz dijo de sus contemporáneos franceses: "Les hemos enviado a Jerry Lewis y ellos nos han contraatacado enviándonos a Jacques Derrida y la desconstrucción." ${ }^{4}$

Cuando Heidegger utilizó el término Destruktion en su obra Ser y tiempo, lo que tenía en mente no era una "destrucción", ni siquiera el "desmantelamiento", sino más bien un "rompimiento del hielo" que había conformado la noción occidental tradicional de "Ser". La "destrucción" de Heidegger no se entendía en un contexto negativo. No tenía intención alguna de liberarse de la tradición ontológica. Como él mismo declara: "El propósito de esta destrucción no es enterrar el pasado en la nulidad de Nichtigkeit." ${ }^{5}$ A Heidegger simplemente no le gustó la manera en que la tradición había concebido la noción de Ser. Quería despejar impedimentos para que se pudiera regresar a la plática de las experiencias primordiales del Ser mismo más que de los "entes" que son sus expresiones, al Sein más que al Seinden.

Mientras que Heidegger en sus últimas obras reemplazaba Destruktion por el término más suave Überwindung (vencimiento), ${ }^{6}$ su discípulo Derrida buscó una línea de desarrollo más rigorista con el uso del término "desconstrucción". En su original obra De Gramatología, Derrida

${ }^{2}$ Maggie Hum, The Dictionary of Feminist Theory, 1990, Columbus, Ohio, Ohio State University Press, p. 239.

${ }^{3}$ Jacques Derrida, Memories: For Paul De Man.

${ }^{4}$ Quoted in Leyman, p. 22.

${ }^{5}$ Martin Heidegger, Being and Time, tr. by John Macquarrie and Edward Robinson, 1992, New York, Harper \& Row, parág. 6, p. 44.

${ }^{6}$ Michael Gelven, A Commentary of Heidegger's "Being and Time", 1970, New York, Harper \& Row, p.31. 
ve a un trabajo no con referencias a algo más allá de sí mismo, de su autor, un mundo o una tradición sino como a un texto exclusivamente autorreferencial, por lo que tanto el "origen" como el "fin" de un texto se detienen en el lenguaje. En el momento en que un texto parece traspasar su propio sistema de significación gramatológica el significado se vuelve "dudoso", según la terminología de Derrida. El objetivo principal del desconstruccionista es abrir la textualidad del texto. ${ }^{7}$ Así, al reducir la "obra" a "texto", en efecto Derrida está reduciendo la filosofía y la teología a gramática.

Para quien ve al lenguaje como la apertura a un mundo de valores reales, el desconstruccionismo es simplemente un camino al nihilismo. Es por ello que el novelista Walker Percy dirá que toda la empresa desconstructivista no es más que un intento de liberarse de Dios por el uso primordial de la gramática. ${ }^{8}$ Sin embargo, parte de la fascinación del desconstructivista es que esta empresa presenta un escape de la cerrazón del conocimiento. La indefinidad del fin abierto de la textualidad, "colocar todo en abismo" (mettre en abîme), ofrece la imagen intoxicante del abismo como la libertad de nunca pisar fondo.'

Desconstruccionismo es casi un sinónimo del posestructuralismo del mundo posmoderno, pues afirma que las estructuras principales por las cuales organizamos nuestro pensamiento no son naturales ni inevitables, sino construcciones artificiales. Por lo tanto, promete sacarnos de nuestra ingenua complacencia para que sólo veamos lo que el texto pueda justificar.

Quizás el primer desconstruccionista reconocido sea el antiguo sofista Gorgias de Leontini (483-376 a.C.). El preocuparse más de la retórica que de la filosofía y el estar más enamorado de las palabras que de la realidad, lo llevaron a escribir un tratado satírico titulado Sobre la

${ }^{7}$ Jacques Derrida, Of Gramatology, tr. by Gayatari Chakravorty Spivak, 1976, Baltimore, John Hopkins University Press, p. XLIX.

${ }^{8}$ Jay Tolson, Pilgrim in the Ruins: A Life of Walker Percy, 1992, New York, Simon \& Schuster, p. 460.

${ }^{9}$ Derrida, 1976, p. LXXVII. 
DONALD DE MARCO

naturaleza o lo no existente, en el cual utilizó el poder de la palabra para desconstruir el mundo. Su razonamiento era el siguiente: ya que la no existencia es no existencia, luego entonces la no existencia es. Como consecuencia, su contraria, la existencia, no es. Por lo tanto, la no existencia es y la existencia no es. Gorgias llegó a afirmar que aun si algo existiera, no podríamos saberlo. Además, en el improbable caso de que pudiéramos conocer algo, no podríamos comunicarlo. ${ }^{10}$

Quizás el ejemplo de desconstrucción más impresionante que aparece en la literatura contemporánea se encuentre en la galardonada novela Life: A User's Manual de George Perec. El personaje principal del libro es un excéntrico multimillonario llamado Percival Bartlebooth, que a los 25 años de edad y fastidiado de la vida, comienza un proyecto de 50 años: ser un ejemplo perfecto de desconstrucción. Durante los primeros diez años toma clases de acuarela todos los días. Durante los siguientes veinte años viaja a 500 puertos distintos donde pinta -uno cada quincena- otros tantos paisajes marinos. A medida que termina cada pintura, la envía a París, donde se transforma en un rompecabezas de exactamente 750 piezas. Cuando acaba con sus pinturas, regresa a casa y comienza un período de 20 años durante el que se dedica a armar los rompecabezas -uno cada dos semanas también. A medida que concluye cada rompecabezas, un experto artesano "lo retexturiza" para que sus líneas se borren y después lo separa de su base. Finalmente, cada pintura es regresada al puerto donde se pintó veinte años antes. Allí la acuarela es tratada con una solución de detergente que la reduce a una capa de papel blanca y sin manchas. El proyecto consiste en "una serie de acontecimientos que, al ser concatenados, se anulan entre sí: comienza de la nada, pasa por operaciones precisas y finaliza en nada"."

${ }^{10}$ Jacques Maritain, Introduction to Philosophy, tr. by E. I. Watkin, 1932, London, Sheed \& Ward, p. 68-9.

${ }^{11}$ Georges Perec, Life: A User's Manual, tr. by David Bellos, 1987, Boston, David R. Godine, p. 118. 
Bartlebooth fracasa en su intento de completar su proyecto, mas no por falta de determinación. A los 75 años y ciego, muere mientras desesperadamente intenta completar el rompecabezas número 439. El proyecto de Bartlebooth, el cual no tiene otro objetivo que el de su mismo cumplimiento, fue su propia respuesta existencial a la incongruencia esencial de la vida. Su trabajo de medio siglo se compararía con la forma en que la muerte desconstruye la vida, la cual emerge por sí misma de la nada a través de un círculo de construcción, reconstrucción y desconstrucción. Bartlebooth comenzaba con nada, avanzaba hacia algo y terminaba con nada. Sólo la experiencia efímera era real. No quedaría nada para la posteridad. No existía un valor trascendente para lo que él hacía o intentaba hacer. Sus lienzos eran los palimpsestos ideales del desconstruccionista cuyo destino inevitable sería borrado. Como Derrida ha aconsejado: debemos poner todo bajo el borrador (sous rature), es decir, pasar la esponja húmeda sobre el pizarrón que contiene palabras escritas. Un lienzo o manuscrito no es más que un palimpsesto que ha sido borrado para que palabras o imágenes nuevas puedan reemplazar a las otras y después sufran el mismo destino.

El desconstruccionismo, en tanto que una filosofía de la vida, es fundamentalmente nihilista ya que sostiene que la nada acabará venciendo al ser. Esta discontinuidad radical es la antítesis lógica de un punto de vista judeocristiano, centrado en la sucesión de vida, muerte y resurrección. Es precisamente en la resurrección donde el desconstruccionista no puede leer el texto de su vida, dado que el desconstruccionismo se opone a cualquier forma de continuidad. Dentro de su perspectiva la cultura aparece como una gran venta de garaje. Se burla de cualquier búsqueda de profundidad, menosprecia el significado de la historia y niega la existencia de cualquier diferencia estética entre Shakespeare y la televisión. Prefiere la libertad a la fidelidad, el sexo al matrimonio y la anticoncepción a la procreación. En las palabras de un crítico, '"el individuo' se ha descompuesto de la misma forma en que la 'realidad' se ha disuelto; sólo tienen vida los 'discursos', 'textos', 'juegos de palabras', 'imágenes', 'simulaciones', en lo que respecta a otros 'dis- 
cursos', 'textos', etc." ${ }^{12}$ La desconstrucción en el mundo posmoderno limita toda forma de gozo a la libertad y la diversión plena.

Un área de la existencia humana que de modo particular ha sido receptiva a la influencia del desconstruccionismo es el de la sexualidad. Desde una perspectiva cristiana tradicional, las relaciones maritales son un acto de amor entre marido y mujer que los une totalmente en cuerpo y alma, y llevan a la pareja a procrear seres a quienes educan como miembros de una familia. Varias líneas de continuidad se asocian con las relaciones maritales. Existe la intimidad entre los cónyuges y el amor encarnado que los lleva a esa unidad. Además, existe la relación de la pareja con Dios, el Autor de la vida, así como la relación de la esposa con la maternidad y del esposo con la paternidad. Finalmente, existen las relaciones esenciales entre todos los miembros de la familia que se integran en una unidad familiar. El matrimonio no es la yuxtaposición de soledades y los cónyuges no son sólo individuos. Los hijos se procrean, no se fabrican y la familia es una unidad orgánica, no un agregado suelto de sujetos aislados.

Como consecuencia, podemos hablar de cinco valores particulares unidos que se alían (al menos potencialmente) a las relaciones maritales: intimidad, encarnación, invocación, identificación e integración. En el mundo posmoderno de la desconstrucción, las nuevas técnicas reproductivas agreden seriamente estos valores tradicionales.

\section{Intimidad}

Cuando Lesley Northrup, una sacerdotisa de la Iglesia Episcopal cumplió cuarenta años, sintió lo que ella llamó "una urgencia profunda de crear y nutrir lo que nadie podría negarle". ${ }^{13}$ No estaba casada ni tenía planes de hacerlo y tenía en mente la adopción de un niño. Con el

${ }^{12}$ Todd Giltin, "Hip-Deep in Post-Modernism," The New York Times, Nov. 6, 1988, Book Review Section 7, p. 35.

${ }^{13}$ Marjorie Hayer, "A Need Examined, a Prayer Fulfilled: Unmarried Priest Bears Child by Artificial Insemination," Washington Post, Dec. 7, 1987, p. 1. 
objeto de satisfacer su deseo, utilizó la autoinseminación durante tres noches consecutivas, usando el esperma de varios donadores. Nueve meses después dio a luz una niña, Evan Arandes Northrup. Seleccionó a sus donantes porque estaban dispuestos a ofrecer su esperma sin aceptar las responsabilidades y preocupaciones normales que implica la paternidad. La señorita Northrup decidió de este modo la concepción de un niño para "desconstruirse" de cualquier asociación con la intimidad (marital o no) así como con el matrimonio mismo o la paternidad. Varios miembros de su familia y también el obispo que la ordenó la apoyaron en su decisión.

Es evidente que desde una perspectiva puramente técnica, la intimidad no es necesaria para que se produzca la concepción. Pero este marco de referencia desconstructivo pierde la objetividad del propósito dominante de hacerse uno en la carne, que tanto implica como ayuda a fomentar la intimidad.

\section{Encarnación}

Los procedimientos de subrogación se realizan de acuerdo con la suposición de que la mujer subrogada, es decir, la que lleva en su seno y alumbra al hijo no reclamará los derechos de ser la madre ni insistirá en tener todos los derechos que una madre tendría en lo que toca a su hijo. Esta suposición se contradice con frecuencia cuando una mujer subrogada cambia de parecer y exige sus derechos de madre. Con el objeto de prevenir que una mujer subrogada viole el acuerdo contractual, algunos abogados han propuesto una nueva definición legal de maternidad, en la cual ésta se desconstruya de cualquier referencia tanto biológica como corporal.

Tradicionalmente, desde el punto de vista legal, el considerar que la madre es la persona de la cual el niño proviene constituye una suposición irrefutable. Andrea Stumpf, al escribir para el Yale Law Journal y en oposición a esta ley sobre la encarnación, ha sugerido que debería haber un nuevo entendimiento legal de maternidad y que éste se 


\section{DONALD DE MARCO}

debe basar no en una concepción biológica, sino en una "concepción mental". La señorita Stumpf argumenta que lo mental supera a lo encarnado y biológico en dos formas decisivas, respecto a la procedencia y a la trascendencia. Ella escribe: "La dimensión psicológica de la procreación precede y trasciende a la biología de la creación." ${ }^{14} \mathrm{En}$ esta instancia, la maternidad "se desconstruye" de cualquier referencia al cuerpo, lo cual habilita una maniobra intrigante, ya que lógicamente otorgaría al padre el derecho de convertirse en madre.

\section{Invocación}

Los seres humanos no se "multiplican" como las células ni se "reproducen" como máquinas ni "crean" como Dios. Hablando de una manera apropiada, los seres humanos "procrean". La palabra "procreación" denota una línea de continuidad entre Dios y el hombre. La procreación de la vida humana proviene del acto creativo de Dios y lo continúa. Dios crea de manera creativa en tanto que asigna a los seres humanos un papel para completar la creación a través de su propio esfuerzo creador. De esta manera los seres humanos pueden participar creativamente en la creación de Dios y extender Su obra a través de la procreación.

En el mundo posmoderno, esta línea de continuidad entre la creación y la procreación ha sido desconstruida. Como ejemplo de esta desconstrucción, Lori Andrews, una fiscal de investigación de la Fundación de la barra de abogados de los Estados Unidos, titula su libro sobre las nuevas tecnologías reproductoras $A$ Consumer's Guide. Al desconstruir al padre creativo y convertirlo en "consumidor", el valor de invocación de la intimidad marital se disuelve. Separada de cualquier relación con el Creador, la generación humana se convierte sim-

${ }^{14}$ Andrea Stumpf, "Redefining Mother: A Legal matrix for New Reproductive Technologies," Yale Law Journal, Nov. 1986, p. 194. 
plemente en la afirmación -a través de los medios naturales o tecnológicos-del presunto "derecho de tener un hijo". ${ }^{15}$

Noel Keane, el intermediario de subrogadas más activo de los Estados Unidos, ha participado en programas de televisión sugiriendo al público que cada individuo tiene el derecho de tener un hijo. Por lo regular, él se refiere a un hijo mediante un acuerdo de subrogación como a la "inversión" de su cliente. Escribe: "¿Cómo puede el marido estar seguro de que él es en realidad el padre de su 'inversión' si no puede aislar a la mujer subrogada de otros contactos masculinos?" 16 A medida que el procreador se convierte en el "consumidor", el vástago humano se desconstruye y deviene un bien o una "inversión". Sin embargo, parecería que la definición desconstruida de la relación paternal, como la que se da entre un consumidor y su inversión, no es congénita en lo que respecta al cultivo de la autoestima del niño o en la misma dignidad del padre.

\section{Identificación}

A través de su relación común con el hijo, tanto el esposo como la esposa consuman la paternidad y la maternidad mutuamente e identifican al niño como a su hijo o hija. Al mismo tiempo, ese niño identifica a sus padres como padre y madre. Para el desconstruccionista, tales identificaciones son puras construcciones arbitrarias. Las identificaciones familiares pueden asignarse también con un fundamento diferente, relacionado con circunstancias específicas.

En un caso muy sonado en Sudáfrica, Pat Anthony de 48 años de edad dio a luz trillizos subrogados a su hija Karen, cuyos óvulos se

${ }^{15}$ Lori Andrews, New Conceptions: A Consumer's Guide to the Newst Infertility Treatments, Including in Vitro Fertilization, Artificial insemination, \& Surrogate Motherhood, 1984, New York, St. Martin's.

${ }^{16}$ Noel Keane with Dennis Breo, The Surrogate Mother, 1981, New York, Everest House, p. 265. 
habian fertilizado in vitro con el esperma de su marido. ${ }^{17}$ De acuerdo con la ley sudafricana, los trillizos -dos niños y una niña- pertenecieron a la señora Anthony hasta que Karen y su marido los adoptaron formalmente. Si la señora Anthony hubiera decidido quedarse con la niña mientras que su hija adoptara a los dos niños, la niña habría sido la tía legal de sus propios hermanos. Antes de la adopción, Karen, que había tomado hormonas durante nueve meses con el objeto de amamantar a los recién nacidos, estaba de hecho y según la ley, amamantando a sus hermanos.

En Canadá, la seudónima Pamela Better sirvió como madre subrogada a su hermana. La señorita Better pudo concebir a través de la inseminación artificial del esperma congelado de su cuñado transportado desde Toronto hasta Vancouver. Más tarde, su hermana y el esposo de ésta adoptaron al niño. A pesar de que la señorita Better concibió, gestó y tuvo al bebé, nunca reclamó ser su madre. En un informe público a la Real Comisión de Nuevas Tecnologías Reproductoras, ella declaró: "Lo que hice fue ser una habitación de hotel durante nueve meses." 18

74 La desconstrucción de las identificaciones familiares conduce a una libertad para reconstruirlas de acuerdo con las preferencias particulares de cada individuo. Sin embargo, no parece probable que los procesos de desidentificación y reidentificación no formen parte del interés del sujeto particular.

\section{Integración}

La calidad orgánica de la familia es más vulnerable a los procesos de desconstrucción. No hay nada que se lea en el "texto" de cualquier

${ }^{17}$ Eric Levin, "Motherly Love Works a Miracle," People, October 19, 1987, p.41.

${ }^{18}$ Mary Lynn Young, "Woman gave birth for her elder sister," Vancouver Sun, Nov. 27, 1990, B1. 
individuo que sugiera la noción de pertenencia a una familia en particular. Así, cuando el matrimonio entre Junior Lewis y Mary Sue Davis se disolvió, parecía lo suficientemente obvio para el señor Dávis que siete embriones congelados que habían sido concebidos a través de la fertilización de los óvulos de su esposa, por medio de su esperma, no formaban parte de su descendencia y, por ende, no eran miembros de la familia. Sin embargo, su esposa pensaba de manera diferente. Mientras que Mary Sue no consideraba a los embriones -que supuestamente estaban todavía vivos en nitrógeno líquido-como sus hijos, sí creía que expresaban "vida". Ella no se consideraba su madre, sino más bien manifestaba la esperanza de que algún día podría convertirse en su madre. ${ }^{19}$

La disputa llegó hasta la corte y el juez Dale Young dictaminó que: "Debido a que la vida humana comienza al momento de la concepción", los siete embriones congelados eran seres humanos y les confirió la custodia a la madre. Tuvo la osadía de regresar los embriones a lo que permanecía en ese momento como una familia no intacta. Sin embargo, fue criticado muy severamente por esta decisión. Un escritor, por ejemplo, lo censuró por emitir una decisión "retrógrada" y se quejó diciendo que el juez no consideraba a los embriones en términos más poéticos ya que los veía como "pléyades congeladas in vitro puestas contra un firmamento de Petri" ${ }^{20} \mathrm{Al}$ identificar los embriones como niños, el juez fue castigado por convertirlos en "personajes antropomórficos de Disney". ${ }^{21}$

El crecimiento y desarrollo de una familia dependen de la buena integración de sus miembros en unidad orgánica. Esta familia integral se desconstruye fácilmente en un ensamblaje de extraños, algo simi-

${ }^{19}$ Jérôme Lejeune, The Concentration Can, 1992, San Francisco, Ignatious Press.

${ }^{20}$ Margaret Doris, "Test-tube ruling: Right decision, wrong reason," The Boston Herald, Oct. 1, 1989, p. 35.

${ }^{21}$ Ibid. 


\section{DONALD DE MARCO}

lar a lo que el psiquiatra David Cooper tenía en mente cuando calificó a la familia como "la última forma de desunión". ${ }^{22}$

La desconstrucción, aun cuando no era conocida con ese término, ha sido una de las fuerzas principales en la historia del pensamiento moderno. Descartes desconstruyó al conocedor convirtiéndolo en pensador; el existencialismo estético desconstruyó a la persona y la convirtió en individuo; el pensamiento posmoderno ha desconstruido a la moralidad convirtiéndola en elección. Al desconstruir el mundo en texto ("Il n'y a rien hors du texte), Derrida simplemente estaba continuando una práctica convertida en inherente al pensamiento moderno. El resultado acumulativo del pensamiento moderno es colocar al pensador amoral en medio del vacío, únicamente preocupado por su individualidad. $^{23}$

En el centro de la tradición tomista se encuentra la institución por la que el orden fluye del Ser. La creación no consiste en una colección de seres que no están relacionados de una manera precisa. Por el contrario, los seres están ordenados unos con otros y con Dios. El pensamiento tomista abarca la continuidad entre el Ser y el Orden. Según Santo Tomás, "el orden de las partes del universo entre sí existe en virtud del orden de todo el universo de Dios". ${ }^{24}$ Más adelante declara: "Lo que viene de Dios se encuentra en un orden perfecto. Ahora, el orden de las cosas consiste en esto, el ser guiadas a Dios las unas con las otras." 25

Para Santo Tomás un conocedor se ordena a las cosas que pueda conocer de una manera cognoscitiva, mientras que una persona se ordena moral y comunitariamente a sus otros prójimos. La moralidad no es una simple elección, sino que se ordena a una consecuencia, y

${ }^{22}$ David Copper, The Death of the Family, 1970, New York, Pantheon books.

${ }^{23}$ Marion Montgomery, "Deconstructionism and Eric Voegelin", Crisis, June 1988, p. 42.

${ }^{24}$ Aquinas, Questiones disputatae de potentia Dei, 7, 9.

${ }^{25}$ Aquinas, Summa Theologica, I-II, 111, 1. 


\section{RESPUESTA TOMISTA A LA DESCONSTRUCCIÓN}

una elección verdaderamente moral se ordena a una buena consecuencia moral. La pauta fundamental de esta filosofía es el orden y la continuidad. Cada ser está rodeado de una gama de referentes. La luz del sol, la humedad y los nutrientes se ordenan al crecimiento y maduración de los cultivos, los cuales, por ejemplo la comida, se ordenan al sistema digestivo, que por ende se ordena a los procesos de asimilación y desarrollo. El punto de vista de los desconstruccionistas de que el mundo es un texto carente de referentes que vayan más allá de sí mismo, no puede defenderse porque se contradice con los hechos más mundanos de la vida.

Walker Percy rebate la noción de que los textos no cuentan con referentes, en su metáfora del hombre que deja un mensaje en la contestadora de su teléfono pidiendo una pizza de peperoni para la cena. Según Percy, el mensaje es el texto y la pizza es el referente. Cuando el dispositivo de autoborrado de la contestadora telefónica elimina el mensaje, no es de sorprenderse que la pizza no llegue a materializarse. Percy ejemplifica el mismo realismo de sentido común que Chesterton señalaba como una característica esencial de la filosofía de Tomás de Aquino. Las palabras reflejan lo que significan de una manera mucho más confiable de lo que los hablantes a veces hacen cuando dan significados arbitrarios. El mismo Santo Tomás llamó la atención en esta paradoja cuando destacó que "la palabra tiene naturalmente mayor conformidad con la realidad que expresa que con la persona que habla, aunque permanezca en el hablante como su sujeto". ${ }^{26}$

Los desconstruccionistas utilizan palabras para negar lo que las palabras significan. Un soneto de Shakespeare no es un soneto de Shakespeare, sino un simple texto desprovisto de cualquier referencia, sea de Shakespeare, de la tradición o de los significados reales de las palabras. Los desconstruccionistas son en particular hostiles con la noción del "logos", especialmente como se presenta en el Evangelio según San Juan. El "logocentrismo" es el enemigo, argumentan, porque afirman que la palabra tiene una afinidad intrínseca con un

${ }^{26}$ Aquinas, De natura verbi intellectus. 
principio racional que opera en el universo y su contraparte cósmica. Además, la Palabra puede hacerse carne; y dos personas que se dan su Palabra en el matrimonio pueden devenir dos personas unidas en una por la carne. El logocentrismo tanto cristiano como tomista enseña que la Palabra y la Realidad no son mutuamente exclusivas.

Los desconstruccionistas pueden parecer humildes y autodestructivos cuando se abstienen de emitir juicios en lo que respecta al significado. Parecen tener una mente abierta y son muy cautelosos cuando declaran que prácticamente todo es indecible. Pero su presunta humildad es más bien una falta de respeto al gran fin del orden de las cosas, mientras que su presunta apertura es más bien un rechazo al reconocimiento de lo evidente.

Las palabras son ventanas por las que aparece un mundo más grande. En las manos del desconstruccionista, estas palabras son espejos que no hacen más que reflejar lo que está en otros espejos. Los textos no hablan sobre el mundo donde se llegó a pensar que el pensamiento residía, sino sobre otros textos, ahora es sólo una infinidad de reflejos en espejos. "Para los desconstruccionistas-como decía un crítico-el mundo está hecho de cuartos vacíos, con paredes impenetrables, sin puertas, donde las mentes de los individuos se dedican a emitir textos con una sonrisa leve." ${ }^{27}$ Uno podría preguntarse cómo los desconstruccionistas pueden ocupar cuartos "vacíos" y sonreír en una atmósfera tan claustrofóbica.

El hecho de que la palabra no pueda abarcar o comprender la realidad que significa, no justifica que ésta abandone su función realista. Lo que sí sugiere es que se deben utilizar palabras para profundizar la apreciación de la riqueza del Ser. El desconstruccionista se aleja de un mundo demasiado grande como para encerrarse, para habitar un mundo demasiado pequeño y así poder disfrutarlo. Intercambia el mundo del Ser por un mundo de palabras y luego intenta convencerse a sí mismo de que ir para atrás es ser progresista. La preferencia tomista es utilizar palabras y ventanas que guíen de un mundo de insularidad

${ }^{27}$ Leyman, p. $21-2$. 


\section{RESPUESTA TOMISTA A LA DESCONSTRUCCIÓN}

verbal al mundo incomparablemente más grande del Ser. Se desplaza de signos a lo que significan estos signos, de las tinieblas a la luz. Éste es el diseño fundamental y la dirección de la vida en general, así como de la relación marital en particular. 